\title{
Preface: The Concept of this Handbook
}

This handbook on 'Autobiography/Autofiction' is a challenge - and a risk. When Manuela Gerlof from de Gruyter proposed to edit a handbook on autobiography, I hesitated at first. As I had already conducted quite a bit of research in the field of autobiography in the German speaking world and on the theory of autobiography, it did not seem all that attractive to undertake another book on autobiography. However, the project started to intrigue me when Dr. Gerlof suggested we publish the handbook in English and place it on the international book market. Having previously dealt mostly with German autobiographies and being familiar mainly with the Western tradition of the genre, the idea of thinking about autobiography in a global and hence transcultural perspective became more and more fascinating. I realized that I did not know anything about autobiographical forms in non-Western cultures and I started to reflect on the question of the extent to which the notion of 'autobiography,' at least in the way we perceive of it in the West, can be considered as a specific Western product. Of course, autobiographies have been and are being written all over the world. Being aware that cultural exchange and hybridity are common features of a globalized world, one has to ask what this means for the genre of autobiography, its different cultural contexts and historical features. These and other enthralling questions finally got the upper hand of my initial scepticism. So I accepted the challenge, although I have always been aware that it will be impossible to represent a genre as mutable as autobiography in a transhistorical global perspective. The idea that this project will allow and necessitate intensive collaboration with autobiography researchers from all over the world allayed the fears of failure. And of course, such a handbook combining all these different approaches - theory, history, and analyses of individual texts - does not yet exist and will be an invaluable tool for students and researchers alike.

The handbook presents the historical and conceptual variety of the autobiographical genre in three volumes. The outline of volume one is theoretical and systematic. Its first section looks at autobiography from the perspective of different disciplines and theoretical approaches. Although literary studies have been investigating the form and historical appearance of autobiography extensively, other disciplines such as history, psychology, religious studies, etc. use autobiographies as sources and have developed their own concepts of the genre. In order to foster the interdisciplinary discussion on autobiography it seems to be important to represent the views and concepts of different disciplines. If a reader has the impression that an article on literary studies is missing from the list of disciplines in the section on "Theoretical Approaches," however, this is certainly due to the blind spot of the editor's own disciplinary background. For a literary scholar, the literary studies perspective constitutes the 'norm,' whereas 'other' fields are 'added' to make the picture complete. This unavoidable disciplinary centrism may be excused by referring to the different methodological approaches that are explained in this first section of volume one as well. They indicate, of course, not only the heterogeneity of approaches within literary 
studies but also forge connections to other disciplines and in this way promote interdisciplinary debate. The second section of volume one discusses categories which hitherto have been applied to the study of autobiography/autofiction. The chapters relate their focus on the autobiographical/autofictional to general literary and cultural studies approaches and elaborate transdisciplinary perspectives. It is the aim of the third section to display the multiplicity of autobiographical forms and genres in the course of history as well as in the present time. The chapters demonstrate the mutability of the genre with special emphasis on its media and intermedial aspects.

Volume two intends to trace the historical development of the autobiographical genre. As one might imagine, doing so on a worldwide scale raises a fundamental yet intriguing problem. Of course it is not possible to tell the history of a genre in a global perspective by following a single timeline, as too many different cultural contexts would have to be considered simultaneously. Therefore, the presentation is structured by proceeding from continent to continent. This, of course, does not solve the problem of concomitance and heterogeneity, yet it helps us to come to grips with it. But where to start? Obviously, all the different options would be biased in some sense. How we start and the routes we take mirror the prejudiced ways we see the world. It is not possible to conceptualize any world order in a neutral way. The problem becomes even more complicated when we look critically at the subject under consideration: autobiographical/autofictional writing. The notion of autobiography that a European literary scholar might develop is formed, at best, by what she considers 'the European tradition.' Being academically and culturally socialized as European may cause her to think that the concept of autobiography is a European one. She might be mistaken, or she might have to alter her idea of 'the autobiographical.' In any case, she must be aware of this specific Western view when looking for authentic forms of the autobiographical in other cultures. Most likely to be found when looking across the globe is a complex and multi-layered meshwork of different autobiographical and autofictional forms and traditions, as cultures today as in the past are much more entangled than we might suspect. This handbook, therefore, undertakes an experiment which may lead to reconsidered notions of autobiography/autofiction. In the meantime, the researcher has to accept her Eurocentric focus and reflect critically on it, using it as a heuristic tool. In doing so, and not considering it as ontologically given, we might find different ways to present our material and develop new perspectives on the variety of autobiographical self-representation.

With the more systematic approach of volume one and the historical procedure of volume two in the background, volume three intends to provide closer looks at individual autobiographical texts. This is not meant to set up an autobiographical canon but to demonstrate the richness of the genre and the complexity of its systematic and historical aspects in individual autobiographical/autofictional texts. The reader may find here famous and less well-known examples side by side. This is intentional. I made suggestions to the contributors of the handbook but was open to their alternative proposals. The authors were asked to write essays on the texts they had chosen 
and were not given strict guidelines about how to structure the chapter. The essays are supposed to give an overview of the state of the research debate but should also be an enjoyable read and spark the reader's curiosity about the autobiographical work being presented.

The different approaches of the handbook's three volumes provide variable and multilayered access to the rich and complex autobiographical paradigm. As a matter of course, the nearly 70 contributors bring in their different individual, cultural, and disciplinary perceptions of their subject. The objective was thereby not to homogenize the chapters in favor of an overarching concept. This would certainly have been wrong, since it would create an illusion of coherence. Instead, it is the aim of this volume to conceptualize the autobiographical genre as multi-perspectival, relational, and mutable. Thus, the three volumes of this handbook, with more than 150 chapters, allow many different paths into and through this fascinating genre. Standardization would also have meant to level out the different academic traditions that have been prevalent in autobiographical research in different parts of the world. Interestingly, the term 'life writing' that is common in the Anglo-Saxon world does not translate for example into German. As 'life writing' also covers the biographical genre, it is a wider category than 'autobiographical writing,' which is more common on the European continent. Here, the debate on 'autofiction' originating from the French context has recently played a major role in academic discourse whereas it has only reluctantly found entry into the English-speaking world. This demonstrates the broad spectrum of subjects, terms, and concepts within the global academic discourse on the topic and the handbook tries to do justice to these differences in dealing with the autobiographical. And, in order to document the academic Western European origin of this project in its very specific historical and conceptual conditionality, the handbook has been given the title Autobiography/Autofiction and not Life Writing. This reflexive, systematic approach distinguishes the handbook for instance from Margaretta Jolly's comprehensive and most impressive Encyclopedia of Life Writing. Autobiographical and Biographical Forms (2001). As can easily be seen, different academic traditions from all over the world enrich the global picture of the autobiographical genre.

In order not to unify more than was necessary, the contributors to the handbook were free to decide whether they would choose British or American English for their chapters. For philological reasons, quotations from primary texts are given first in the original language and then [in square brackets] in an English translation. This procedure, astonishingly, has caused irritations among contributors, especially among those writing on non-European subjects and using non-Latin characters. Whereas it has not been considered problematic for contributors who wrote about autobiographical texts in European languages, colleagues who are specialists for non-European literatures were somewhat reluctant to quote in Chinese, Japanese, or Arabic. They found that using non-Latin characters in the context of Latin script would make the text uneasy and the reading uncomfortable. This was quite an interesting experience for me, who, on the one hand, as a philologist, wanted to be as close to the origi- 
nal text, and, on the other hand, considers plurality and heterogeneity as something positive and thrilling. Well, compromises were made by using non-European characters in a somewhat allotted and attenuated form. This may seem a bit unmethodical, and indeed it is, yet it may be seen as a concession to both the diversity of the world and heterogeneous academic practices. Published translations in the running text are marked by double quotes and chapter authors' own translations are presented in single quotes.

Such a project as a three-volume handbook has many people to thank: First, I have to thank Dr. Manuela Gerlof, who initiated the project and always believed in its success without ever pushing the work process more than was necessary. And I am happy to say thank you to a wonderful and witty team that, over the years, never seemed to run out of enthusiasm for the project and patience for the arduous details of editorial handwork: especially Kerstin Wilhelms, Thomas Kater, Laura Reiling, and Till Lorenzen, as well as, at the very beginning, Lukas Ricken and, later on, Sarah Maaß. Claudia Altrock, Peter Klingel, Wolf Wellmann, Elena Göbel, Katharina Grabbe, Carolina Ihlenfeld, Leona Lucas, and Paula Marie Stevens assisted magnificently with the indices. Without you all the handbook would not have seen the light of day! I would like to thank Thomas Bauer and Stephan Tölke, who helped with the Arabic, as well as Regina Grundmann and Sarah Rürup for their assistance with the Yiddish. The Cluster of Excellence "Religion and Politics in Pre-Modern and Modern Times" at the University of Münster gave financial support. The Internationales Kolleg Morphomata (Centre for Advanced Studies) at the University of Cologne granted me a research semester to work on the handbook. I am also grateful to Charlton Payne, who patiently edited the English of many articles (including this one). Last but not least, I would like to express my gratitude to the contributors to this handbook, who wrote wonderful texts and who had to endure the editor's insistence. The handbook is as much yours as it is mine! 